\title{
Maturation of mouse oocytes in vitro is influenced by alkalization during their isolation
}

\author{
P. V. Bagger, A. G. Byskov* and M. D. Christiansen* \\ Department of Obstetrics and Gynaecology 537, Hvidovre Hospital, Kettegaard Alle, \\ $D K-2650$ Hvidovre, and ${ }^{*}$ Laboratory of Reproductive Biology II, Section 4112, Rigshospitalet, \\ University of Copenhagen, Blegdamsvej 9, DK-2100 Copenhagen Ø, Denmark
}

\begin{abstract}
Summary. Dictyate oocytes were isolated from the ovaries of 22-day-old mice and cultured for $24 \mathrm{~h}$. Isolation and classification of the oocytes were done at a stable $\mathrm{pH}$ of $7 \cdot 45$, during gradual increase of $\mathrm{pH}$ from $7 \cdot 45$ to $8 \cdot 3$, or at $\mathrm{pH} 8 \cdot 3$. In cumulus-enclosed oocytes alkalization beyond $\mathrm{pH} 7.45$ resulted in an increased rate of degeneration and decreased rates of germinal vesicle breakdown and polar body formation. In the naked oocytes, only the rate of degeneration was affected. The results stress the importance of a stable $\mathrm{pH}$ during the period of isolation, and of a careful classification of the oocytes before culture.
\end{abstract}

\section{Introduction}

Maturation in vitro of fully grown mammalian dictyate (diplotene) oocytes provides a practical method for the study of meiosis. The basic requirements for culture of oocytes are well established (Biggers, 1972), but conditions for oocyte isolation before culture have not yet been thoroughly considered. However, occasional comments on the procedure for isolation are found in the literature: Schultz et al. (1983) isolated 150-200 oocytes within $20 \mathrm{~min}$, Donahue (1968) carried out the isolation in drops of medium under oil, whereas Eppig \& Koide (1978), Paleos \& Powers (1981), Schultz et al. (1983) and Salustri et al. (1985) used medium supplemented with Hepes buffer. As the isolation procedure is considered to be crucial, we have investigated the maturation and degeneration in vitro of mouse dictyate oocytes as a function of alkalization during the period of isolation of the oocytes.

\section{Materials and Methods}

Culture medium. Modified Eagle's Minimum Essential Medium (Flow Laboratories Ltd, Irvine, Ayrshire, U.K.: cat. no. 12-312-54) was supplemented with (per $50 \mathrm{ml}$ ) 5000 i.u. G-penicillin, $5000 \mu \mathrm{g}$ streptomycin (Flow Labs: cat. no. 16-700-49), 0.2 mM L-glutamine (Flow Labs: cat. no. 16-801-49) and $1 \mathrm{~g}$ vegetable protein (Ultroser-G; LKB, Copenhagen, Denmark, cat. no. 259501). The concentration of $\mathrm{HCO}_{3}{ }^{-}$and $\mathrm{H}_{2} \mathrm{PO}_{4}^{-}$were $23.8 \mathrm{~mm}$ and $1.0 \mathrm{~mm}$, respectively. The medium had a pH of $7.17 \pm 0.01$ when equilibrated in $5 \% \mathrm{CO}_{2} /$ air and $8.27 \pm 0.04$ in equilibration with air. The osmolality was $279 \pm 2 \mathrm{mosmol} / \mathrm{kg}$.

Animals. The mice were randomly bred females (A-Strong), 22 days of age and weighing $8-12.5 \mathrm{~g}(10.7 \pm 1.4 \mathrm{~g}$ per mouse). They were housed in air-conditioned quarters, lights on between 06:00 and 18:00 $\mathrm{h}$, and with water and pelleted food available ad libitum. The mice were killed by cervical dislocation.

General conditions for oocyte isolation. One mouse was killed at a time and handled immediately. Isolation of the oocytes was carried out in a flow hood, under a stereo-microscope, in two drops of warm $\left(36^{\circ} \mathrm{C}\right)$ medium. Each drop had a volume of $\sim 1.3 \mathrm{ml}$ and a diameter of $\sim 2.5 \mathrm{~cm}$. In the first drop fat and appending tissue were removed from the ovaries using hypodermic needles. In the second drop follicular puncture was carried out using a new pair of needles. Some oocytes were released by carefully scraping the ovarian surface. Then the ovary was cut into smaller pieces and oocytes of more centrally located antral follicles were released by follicular puncture. Loose granulosa cells were removed from the drop using a handdrawn glass pipette (i.d. $\sim 250 \mu \mathrm{m})$. Each oocyte was rolled over the bottom of 
the dish while being examined and classified at $\times 50$ magnification. Spherical oocytes with a diameter of 75-85 $\mu \mathrm{m}$ and a germinal vesicle with one or two nucleoli were isolated (Erickson \& Sorensen, 1974). Oocytes which were completely covered with firmly attached granulosa cells (cumulus-enclosed oocytes) were transferred to $500 \mu \mathrm{l}$ medium in one well (4-well multidish; NUNC, Roskilde, Denmark: cat. no. 134673) while incompletely covered and naked oocytes (naked oocytes) were pooled in another well.

Using this procedure oocyte isolation took $30-45 \mathrm{~min}$ after the mouse was killed. Altogether, 1886 oocytes from 30 mice $(62 \cdot 9 \pm 22.0$ per mouse) were thus isolated and cultured: 626 oocytes $(20.9 \pm 9 \cdot 4$ per mouse) were cumulusenclosed and $1260(42 \cdot 0 \pm 18 \cdot 1$ per mouse $)$ were naked.

Fluctuations of $\mathrm{pH}$ and osmolality during oocyte isolation. Osmolality and $\mathrm{pH}$ in the drops of culture medium used for isolation were measured as a function of time under two special conditions: (i) with humidified warm (36 $\left.{ }^{\circ} \mathrm{C}\right) 5 \%$ $\mathrm{CO}_{2}$ /air continuously blowing over the drops of medium which had been pre-equilibrated towards the gas, and (ii) without the gas blowing over the drops of pre-equilibrated medium. Osmolality was determined with a vapour pressure osmometer (Wescor Inc., Logan, Utah, U.S.A.: cat. no. 5100-B), and for the measurement of pH we used an analyser for ionized calcium (ICA-1; Radiometer, Copenhagen, Denmark: cat. no. 390-911).

The oocytes were isolated under three special conditions. (A) Isolation was carried out with humidified, warm $5 \%$ $\mathrm{CO}_{2}$ /air blowing continuously over the drops of medium which had been pre-equilibrated towards the gas. This experiment comprised 522 oocytes from 9 mice $(58 \cdot 0 \pm 17 \cdot 1$ per mouse); 199 oocytes $(22 \cdot 1 \pm 9 \cdot 3$ per mouse) were cumulus-enclosed and 323 oocytes $(35.9 \pm 9.8$ per mouse) were naked. (B) For isolation without gas blowing over the pre-equilibrated drops we used 1109 oocytes from 15 mice $(73.9 \pm 19 \cdot 2$ per mouse); there were $323(21.5 \pm 9.9$ per mouse) cumulus-enclosed oocytes while 786 oocytes $(52.4 \pm 17.5$ per mouse) were naked. (C) Isolation was carried out in medium equilibrated towards air. In this experiment we used 255 oocytes from 6 mice ( $42.5 \pm 19 \cdot 4$ per mouse) of which $104(17 \cdot 3 \pm 8.7$ per mouse) were cumulus-enclosed and 151 (25.2 \pm 12.4 per mouse) were naked.

Classification of oocytes after culture. The oocytes were cultured for $24 \mathrm{~h}$ at $36^{\circ} \mathrm{C}$ in an humidified atmosphere of $5 \% \mathrm{CO}_{2}$ /air. After culture they were re-examined under the stereo-microscope at $\times 50$ magnification and, again, rolled while examined. Each group of oocytes was divided into four classes: (i) degenerated oocytes, i.e. non-spherical, granulated, vacuolized or fragmented (von Weymarn et al., 1980), (ii) germinal vesicle intact, (iii) germinal vesicle breakdown without polar body formation and (iv) polar body formation. If necessary for the classification, the granulosa cells were removed by sucking the oocytes in and out of a hand-drawn glass pipette (i.d. $\sim 100 \mu \mathrm{m}$ ).

Statistical methods. The results were expressed as follows: (i) degenerated oocytes as a fraction of all oocytes; (ii) oocytes with germinal vesicle breakdown as a fraction of all non-degenerated oocytes; and (iii) oocytes which formed a poiar body as a fraction of all non-degenerated oocytes with GVBD. The results were reported as variations between mice, i.e. mean \pm 1 s.d. For statistical calculations we used the paired Student's $t$ test and the Wilcoxon rank sum test. A probability of $<0.05$ was regarded as significant.

\section{Results}

\section{Fluctuations of osmolality and $p H$ during oocyte isolation}

Blowing $5 \% \mathrm{CO}_{2} /$ air continuously over the drops stabilized $\mathrm{pH}$ at about 7.45 after $20 \mathrm{~min}$. If this simple procedure was omitted, $\mathrm{pH}$ continued to increase as the medium gradually equilibrated towards air (Fig. 1). The osmolality in the drops of medium increased from $279 \pm 3$ mosmol $/ \mathrm{kg}$ at time zero to $300 \pm 7 \mathrm{mosmol} / \mathrm{kg}$ after $45 \mathrm{~min}$ whether or not humidified $5 \% \mathrm{CO}_{2} /$ air was continuously blowing over the drops.

\section{The influence of fluctuations of osmolality and $\mathrm{pH}$ on the oocyte}

When $\mathrm{pH}$ was stabilized at 7.45 during oocyte isolation polar body formation in cumulusenclosed oocytes exceeded polar body formation in the naked oocytes $(P<0.05)$. Moreover, the two groups were influenced differently by the alkalization beyond $\mathrm{pH} 7.45$ during the oocyte isolation (Fig. 2). In the cumulus-enclosed oocytes degeneration increased $(P<0.01)$ while the rates of germinal vesicle breakdown and polar body formation decreased $(P<0.01)$. In the naked oocytes only the rate of degeneration was affected $(P<0.01)$. The fluctuation of osmolality did not affect degeneration since no degenerated oocytes were observed when $\mathrm{pH}$ during isolation was kept below $7 \cdot 45$. 


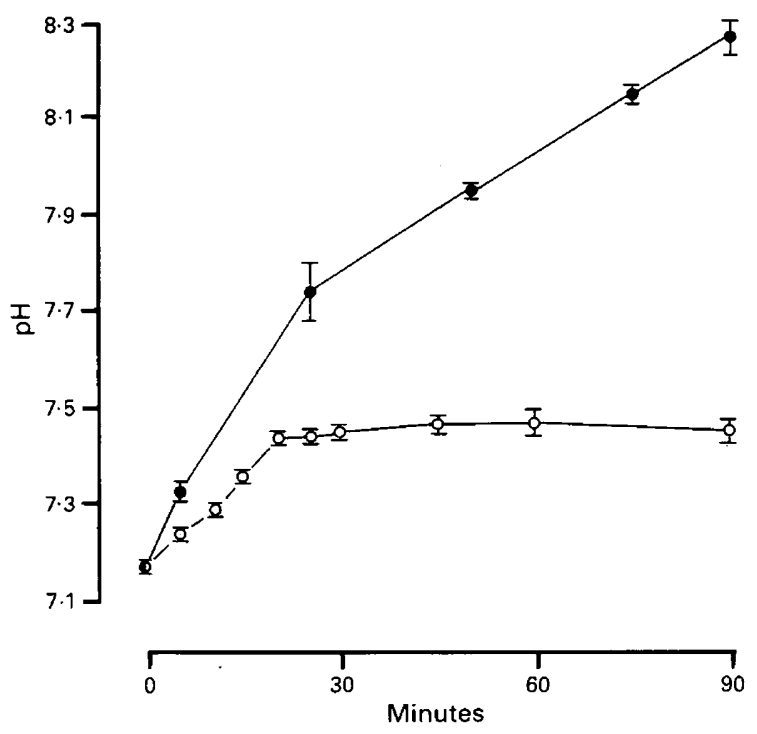

Fig. 1. Fluctuations of the $\mathrm{pH}$ in drops of isolation medium (volume $\sim 1.3 \mathrm{ml}$; diameter $\sim 2.5 \mathrm{~cm}$ ) as a function of time. The medium was pre-equilibrated towards $5 \% \mathrm{CO}_{2} /$ air (time zero). Results are shown as mean \pm 1 s.d. of 5 measurements, only one measurement being performed on each drop. $\bigcirc, 5 \% \mathrm{CO}_{2}$ /air was continuously blown over the drops; $\bullet$, no gas was blown over the drops.
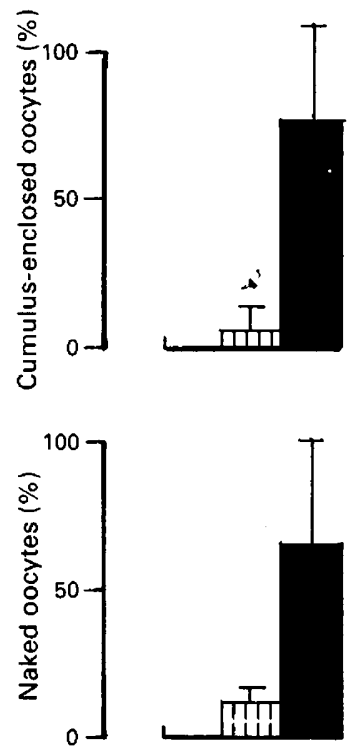

(a)
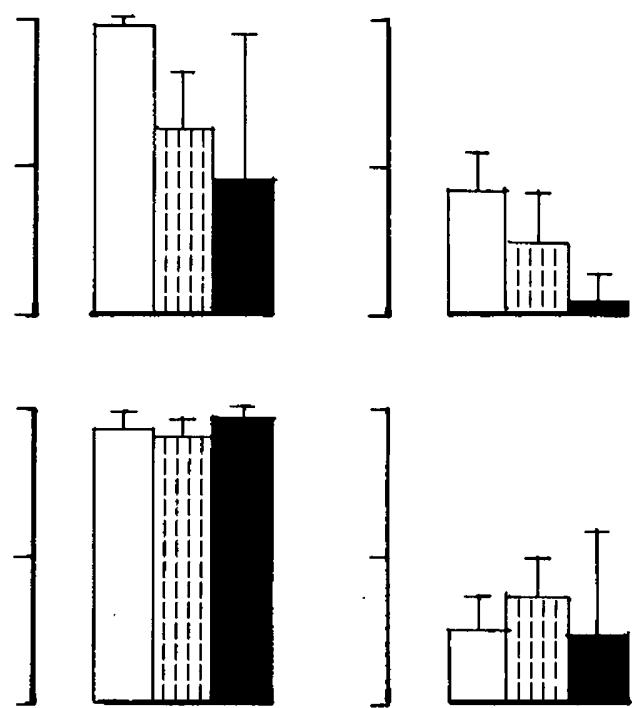

(b)

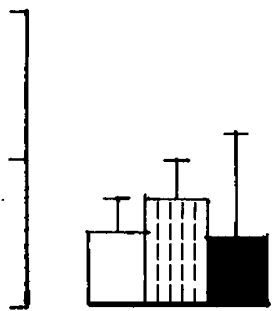

(c)

Fig. 2. Degeneration and maturation of mouse dictyate oocytes after $24 \mathrm{~h}$ in culture as a function of the $\mathrm{pH}$ during the $30-45 \mathrm{~min}$ used for isolation of the oocytes before culture. The oocytes had either a complete, firm cumulus (cumulus-enclosed oocytes) or an incomplete or absent cumulus (naked oocytes). $\square: \mathrm{pH}$ increased from $7 \cdot 2$ at the beginning of isolation but did not exceed 7.45; 贯: $\mathrm{pH}$ increased from $7 \cdot 2$ and exceeded $7 \cdot 45 ; \mathbf{0}: \mathrm{pH}$ fixed at $8 \cdot 3$. The results are shown as variations between mice (mean \pm 1 s.d.). (a) no. of degenerated oocytes/total no. of oocytes isolated; (b) no. of oocytes with germinal vesicle breakdown/no. of non-degenerated oocytes; (c) no. of oocytes forming a polar body/no. of oocytes with germinal vesicle breakdown. 


\section{Discussion}

Isolation of oocytes was completed within 30-45 min after the mouse was killed, which is longer than reported by Schultz et al. (1983). Each oocyte was rolled over the bottom of the dish and sucked in and out of the pipette while examined. Only then could we determine whether the cumulus was firmly attached to the oocyte. Also, only by rolling each oocyte was it possible to distinguish a complete cumulus from an incomplete one, and locate the germinal vesicle in cumulus-enclosed oocytes, and evaluate whether the form of each oocyte was spherical. Frequently oocytes had the form of little hats. They typically showed the convex side to the investigator. If not rolled they were easily interpreted as spherical and, therefore, as healthy.

Other workers have used denuded oocytes (Erickson \& Sorensen, 1974; Eppig \& Koide, 1978; Schultz et al., 1983; Canipari et al., 1984; Salustri et al., 1985), and obtained the advantages of a one-compartment model. We have avoided denuding for two reasons. First, it is very difficult to remove an immature, firmly attached cumulus mechanically (Shea et al., 1975) and, second, the oocyte-cumulus complex should be regarded as a functional entity. The intimate cell-to-cell contact between the oocyte and its cumulus breaks up in atretic follicles (Byskov, 1978). Therefore, dictyate oocytes with a complete firm cumulus probably originate from healthy follicles, while the naked oocytes come from follicles at various stages of atresia. These two groups of oocytes have a slightly different potential for polar body formation in vitro. Moreover, Schroeder \& Eppig (1984) found that the frequency of fertilization in vitro was significantly higher in oocytes matured in the presence of an intact cumulus than in oocytes denuded of their cumulus cells. This may indicate that the potential of the oocyte to complete a normal first meiotic division is influenced by the cumulus cells and that this event is probably disturbed by denudation.

The osmolality in the drops of culture medium increased from 280 to $300 \mathrm{mosmol} / \mathrm{kg}$ after 45 min due to evaporation. Blowing humidified $5 \% \mathrm{CO}_{2}$ /air continuously over the drops did not increase the osmolality further. However, by using this simple procedure the $\mathrm{pH}$ of the drops of medium during isolation could be controlled. By blowing the gas continuously over the drops the $\mathrm{pH}$ was stabilized at about $7 \cdot 45$. Without gas blowing over the drops the $\mathrm{pH}$ continued to increase as the medium gradually equilibrated towards air. Other workers have stabilized $\mathrm{pH}$ with Hepes buffer (Eppig \& Koide, 1978; Paleos \& Powers, 1981; Schultz et al., 1983; Salustri et al., 1985). In a preliminary study we found a large increase of degeneration when the oocytes were cultured in the presence of $10 \%$ Hepes buffer.

The rate of oocyte degeneration partly reflects the quality of the in-vitro system, including the conditions for oocyte isolation, and partly the inability of the observer to isolate only the healthy oocytes. The fluctuation of osmolality did not affect the frequency of oocyte degeneration, since no degenerated oocytes were observed when the $\mathrm{pH}$ during isolation was stabilized as described. However, if the $\mathrm{pH}$ during isolation was allowed to exceed $7 \cdot 45$, degeneration in both groups of oocytes markedly increased.

Not only degeneration per se but also maturation was affected by an increased $\mathrm{pH}$. With the gas blowing over the drops during isolation the rates of GVBD and polar body formation were comparable to those in previous studies in which unstimulated mice of the same age were used (Sorensen \& Wassarman, 1976; Eppig \& Koide, 1978). However, omission of the gas flow, i.e. elevation of the $\mathrm{pH}$ beyond $7 \cdot 45$, affected the maturation of the cumulus-enclosed oocytes, whereas the naked oocytes matured equally well. In the cumulus-enclosed oocytes both the rate of GVBD and the rate of polar body formation decreased with an elevated $\mathrm{pH}$. Whether this difference was due to qualities of the granulosa cells and/or to the oocyte itself is unknown. Alkalization may cause decomposition of nucleic acids in granulosa cells. This may lead to higher levels of hypoxanthine which, according to Eppig et al. (1985), is a potent inhibitor of maturation. However, Houle \& Wassarman (1983) observed that $\mathrm{pH}$ in Xenopus oocytes increased from $7 \cdot 14$ to $7 \cdot 56$ during maturation in vitro. If this is also valid in mouse oocytes mild alkalization may be harmless or even stimulating for oocyte maturation in vitro. 
We thank Mrs T. Roed for technical assistance and Mrs K. Grüning for typing the manuscript. The work was supported by the Danish Medical Research Council Grant No 12-5585.

\section{References}

Biggers, J.D. (1972) Metabolism of the oocyte. In Oogenesis, pp. 241-251. Eds J. D. Biggers \& A. W. Schuetz. University Park Press, Baltimore.

Byskov, A.G. (1978) Follicular atresia. In The Vertebrate Ovary, pp. 533-562. Ed. R. E. Jones. Plenum Publishing Corporation, New York.

Canipari, R., Palombi, F., Riminucei, M. \& Mangia, F. (1984) Early programming of maturation competence in mouse oogenesis. Devl Biol. 102, 519-524.

Donahue, R.P. (1968) Maturation of the mouse oocyte in vitro. I. Sequence and timing of nuclear progression. J. exp. Zool. 169, 237-250.

Eppig, J.J. \& Koide, S.L. (1978) Effects of progesterone and oestradiol-17 $\beta$ on the spontaneous meiotic maturation of mouse oocytes. J. Reprod. Fert. 53, 99-101.

Eppig, J.J., Ward-Baily, P.F. \& Coleman, D.L. (1985) Hypoxanthine and adenosine in murine ovarian follicular fluid: concentrations and activity in maintaining oocyte meiotic arrest. Biol. Reprod. 33, 1041-1049.

Erickson, G.F. \& Sorensen, R.A. (1974) In vitro maturation of mouse oocytes isolated from late, middle, and pre-antral Graafian follicles (1). J. exp. Zool. 190, $123-127$.

Houle, J.G. \& Wassarman, W.J. (1983) Intracellular pH plays a role in regulating protein synthesis in Xenopus oocytes. Devl Biol. 97, 302-312.
Paleos, G.A. \& Powers, R.D. (1981) The effect of calcium on the first meiotic division of the mammalian oocyte. J. exp. Zool. 217, 409-416.

Salustri, A., Petrungaro, S., De Felici, M., Conti, M. \& Siracusa, G. (1985) Effect of follicle-stimulating hormone on cyclic adenosine monophosphate level and on meiotic maturation in mouse cumulus cellenclosed oocytes cultured in vitro. Biol. Reprod. 33, 797-802.

Schroeder, A.C. \& Eppig, J.J. (1984) The developmental capacity of mouse oocytes that matured spontaneously in vitro is normal. Devl Biol. 102, 493- 497.

Schultz, R.M., Montgomery, R.R. \& Belanoff, J.R. (1983) Regulation of mouse oocyte meiotic maturation: implication of a decrease in oocyte cAMP and protein dephosphorylation in commitment to resume meiosis. Devl Biol. 97, 264-273.

Shea, B.F., Baher, R.D. \& LaTour, J.P. (1975) Human follicular oocytes and their maturation in vitro. Fert. Steril. 26, 1075-1082.

Sorensen, R.A. \& Wassarman, P.M. (1976) Relationship between growth and meiotic maturation of the mouse oocyte. Devl Biol. 50, 531-536.

von Weymarn, N., Guggenheim, R. \& Müller, H. (1980) Cytogenetic investigations on development and degeneration of oocytes from juvenile mice. Anat. Embryol. 161, 9-18.

Received 17 September 1986 